\title{
Forced mergers on bank efficiency and productivity: evidence from semi-parametric Malmquist productivity index
}

\begin{abstract}
The paper examines the impact of mergers and acquisitions on the productivity of the Malaysian banking sector. The analysis consists of two stages. Firstly, the semi-parametric Malmquist productivity index (MPI) method is applied to a $[-5,+8]$ window to examine the efficiency and productivity of the acquiring and target banks during the pre- and post-merger periods. Secondly, as suggested by Banker and Natarajan (2008), we employ a battery of parametric and non-parametric univariate tests to examine the difference in the efficiency and productivity of the Malaysian banking sector during the pre- and post-merger periods. We find that the Malaysian banking sector has exhibited a higher total factor productivity level during the post-merger period attributed to technological progress. The empirical findings do not provide conclusive evidence on the less productive banks becoming the target for acquisitions.
\end{abstract}

Keyword: Banks; Forced mergers and acquisitions; Malaysia; Semi-parametric Malmquist productivity index; Total factor productivity change 